Check for updates

Cite this: RSC Adv., 2019, 9, 11585

Received 8th January 2019

Accepted 2nd April 2019

DOI: $10.1039 / \mathrm{c} 9 \mathrm{ra} 00155 \mathrm{~g}$

rsc.li/rsc-advances

\section{Asymmetric synthesis of multifunctional aryl allyl ethers by nucleophilic catalysis $\uparrow$}

\author{
Shuai Zhao, (D) Lei Jin, Zhi-Li Chen, Xue Rui, Jia-Yi He, Ran Xia, Ke Chen, \\ Xiang-Xiang Chen, Zi-Jian Yin and Xin Chen (DD*
}

Asymmetric allylic substitution of Morita-Baylis-Hillman (MBH) carbonates with less-nucleophilic phenols mediated by nucleophilic amine catalysis was successfully developed. A variety of substituted aryl allyl ethers were afforded with moderate to high yields with excellent enantioselectivities. The chiral $\mathrm{MBH}$ alcohol could be easily accessed from the corresponding aryl allyl ether.
Morita-Baylis-Hillman (MBH) reactions provide efficient highly functionalized synthons to be used in the total synthesis of natural products and biologically relevant compounds. ${ }^{1}$ In particular, asymmetric transformations of racemic $\mathrm{MBH}$ carbonates and acetates have provided straightforward access to a wide variety of optically active molecules on the basis of allylic substitution reactions, formal 1,3-dipolar cycloadditions and miscellaneous transformations. ${ }^{2}$ Asymmetric allylic substitution of racemic MBH carbonates and acetates by nucleophiles (nitrogen, oxygen, carbon, etc.) under the catalysis of transition metal complexes ${ }^{3}$ or organocatalysts ${ }^{2}$ has been extensively explored in the past few decades. Reactions with nucleophilic oxygen result in formation of chiral MBH alcohols or ethers, which are synthetically useful building blocks ${ }^{1 b, 4}$ and bioactive molecules. ${ }^{5}$ Despite a few nucleophilic $O$-substitution reactions of $\mathrm{MBH}$ carbonates and acetates under the catalysis of palladium $^{6}$ or organocatalysts 7 that have been developed, there are still many limitations for the enantioselectivity, chemical yields and generality of the substrates, especially when the lessnucleophilic phenols were used. ${ }^{7 f-7 h}$ Therefore, the development of efficient protocols to access enantiomerically pure $\mathrm{MBH}$ alcohols and ethers is still in demand.

As part of our on-going program on developing novel and practical catalytic asymmetric transformations, ${ }^{8}$ we herein present an asymmetric allylic $O$-substitution reaction of $\mathrm{MBH}$ carbonate with less-nucleophilic phenols mediated by nucleophilic amine catalyst. After a careful investigation of the reaction conditions, asymmetric allylic substitution of MoritaBaylis-Hillman (MBH) adducts with less-nucleophilic phenols was successfully developed. An array of substituted chiral aryl allyl ethers were obtained with excellent enantioselectivities. Chiral aryl allyl ethers are valuable substructures and synthetic

School of Pharmaceutical Engineering \& Life Science, Changzhou University, Changzhou, 213164, P. R. China. E-mail:Xinchen@cczu.edu.cn

$\dagger$ Electronic supplementary information (ESI) available: Experimental procedures, analytical data and NMR spectra. See DOI: 10.1039/c9ra00155g intermediates of many naturally occurring molecules and pharmaceutical compounds..$^{5,9}$ Moreover, chiral MBH alcohol could be directly accessed from the final product.

We initiated the study by investigating the reaction of phenol 2a and MBH carbonate 3a in DCM at room temperature. A series of cinchona alkaloids and their derivatives were screened as catalysts (Fig. 1). ${ }^{2 c}$ The results are outlined in Table 1 . Unmodified cinchona alkaloids quinine $1 \mathrm{a}$ and quinidine $\mathbf{1 b}$ gave the desired product $\mathbf{4 a}$ with very high yields but with very low ee values (Table 1, entries 1-2). Protecting the hydroxyl group of $\mathbf{1 b}$ gave 1c and 1d, respectively. But both catalysts resulted in decreased yields and very poor ee values (Table 1, entries $3-4$ ).

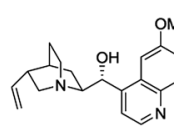

1a

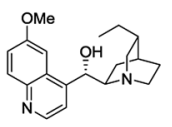

1e
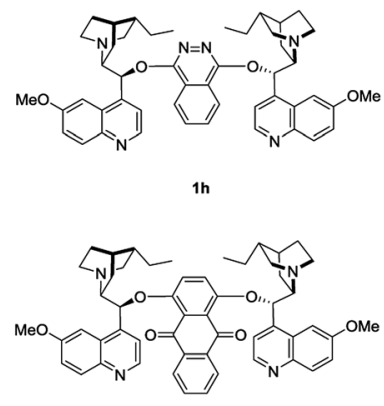

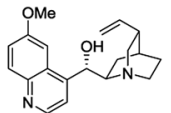

$1 \mathrm{~b}$

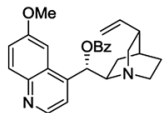

$1 c$

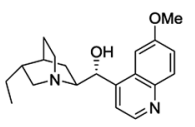

1f

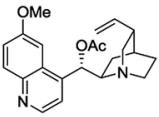

1d

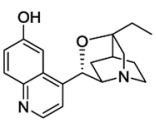

19

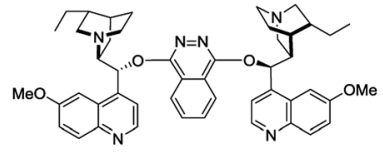

$1 \mathrm{i}$

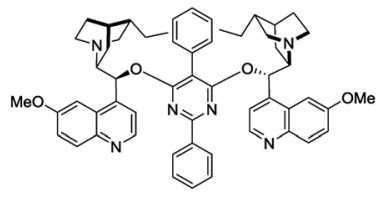

$1 k$
Fig. 1 Chiral nucleophilic catalysts screened. 
Table 1 Optimization of reaction parameters ${ }^{a}$

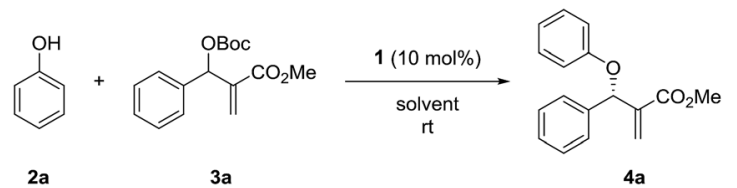

\begin{tabular}{lllllll}
\hline & & & & & \\
Entry & $\mathbf{1}$ & Solvent & $\left(\mathrm{mol} \mathrm{L}^{-1}\right)$ & $t(\mathrm{~h})$ & Yield $^{b}(\%)$ & ee $^{c}(\%)$ \\
\hline 1 & $\mathbf{1 a}$ & DCM & 0.2 & 24 & 94 & -4 \\
2 & $\mathbf{1 b}$ & DCM & 0.2 & 22 & 98 & 7 \\
3 & $\mathbf{1 c}$ & DCM & 0.2 & 72 & 58 & 10 \\
4 & $\mathbf{1 d}$ & DCM & 0.2 & 72 & 37 & 8 \\
5 & $\mathbf{1 e}$ & DCM & 0.2 & 72 & 67 & 7 \\
6 & $\mathbf{1 f}$ & DCM & 0.2 & 48 & 95 & -3 \\
7 & $\mathbf{1 g}$ & DCM & 0.2 & 48 & 77 & -45 \\
8 & $\mathbf{1 h}$ & DCM & 0.2 & 72 & 84 & 41 \\
9 & $\mathbf{1 h}$ & DCM & 0.1 & 66 & 30 & 79 \\
$10^{d}$ & $\mathbf{1 h}$ & DCM & 0.1 & 72 & 79 & 73 \\
$11^{e}$ & $\mathbf{1 h}$ & DCM & 0.1 & 120 & 91 & 74 \\
$12^{e}$ & $\mathbf{1 h}$ & DCM & 0.05 & 84 & 51 & 76 \\
$13^{e, f}$ & $\mathbf{1 h}$ & DCM & 0.05 & 84 & 92 & 77 \\
$14^{e, f}$ & $\mathbf{1 h}$ & 1,4-Dioxane & 0.05 & 96 & 95 & 95 \\
$15^{e, f}$ & $\mathbf{1 i}$ & 1,4-Dioxane & 0.05 & 75 & 68 & -73 \\
$16^{e, f}$ & $\mathbf{1 j}$ & 1,4-Dioxane & 0.05 & 52 & 94 & 86 \\
$17^{e, f}$ & $\mathbf{1 k}$ & 1,4-Dioxane & 0.05 & 52 & 93 & 89
\end{tabular}

${ }^{a}$ Unless otherwise noted, the reaction was carried out with 2a $(0.1$ $\mathrm{mmol})$, 3a $(0.1 \mathrm{mmol})$ and $\mathbf{1}(10 \mathrm{~mol} \%)$ in specified solvent at room temperature. ${ }^{b}$ The isolated yield. ${ }^{c}$ Determined by HPLC. ${ }^{d}$ The reaction was carried out with $0.2 \mathrm{mmol} 3 \mathrm{a} .{ }^{e}$ The reaction was carried out with $0.3 \mathrm{mmol} 3 \mathrm{a}^{f}{ }^{f}$ The reaction was carried out with $20 \mathrm{~mol} \% 1$.

After the double bonds in $\mathbf{1 a}$ and $\mathbf{1 b}$ were hydrogenated, the resulting catalysts $1 \mathrm{e}$ and $\mathbf{1 f}$ failed to improve the enantioselectivity of the asymmetric allylic substitution reaction (Table 1 , entries 5-6). In addition, $\beta$-isocupreidine ( $\beta$-ICD, 1g) gave the desired product in $77 \%$ yield and $45 \%$ ee (Table 1, entry 7 ). When the cinchona alkaloid dimer (DHQD) $)_{2} \mathrm{PHAL}(\mathbf{1 h})$ was tested as the catalyst, the product was obtained in $84 \%$ yield and $41 \%$ ee (Table 1, entry 8). At a lower concentration of $2 \mathrm{a}$ (from $0.2 \mathrm{M}$ to 0.1 $\mathrm{M})$ and under the catalysis of $\mathbf{1 h}(10 \mathrm{~mol} \%)$, the ee value of $4 \mathbf{a}$ was greatly improved (from $41 \%$ to $79 \%$ ), although the yield was decreased (Table 1, entry 9). In order to increase the yield, more amounts of $3 \mathbf{a}$ ( 2 and 3 equivalents to $2 \mathbf{a}$ ) and extended reaction time were used, and resulted in significantly improved yields (from $30 \%$ to $79 \%$ and $91 \%$ ) and with slightly decreased ee values (73\% and $74 \%$ ) (Table 1, entries 10-11). After the concentration of $2 \mathbf{a}$ was further diluted to $0.05 \mathrm{M}, \mathbf{4 a}$ was obtained in $51 \%$ yield and $76 \%$ ee (Table 1 , entry 12 ). When $20 \mathrm{~mol} \% \mathbf{~} \mathbf{h}$ was used at this concentration of $\mathbf{2 a}$, the desired product $\mathbf{4 a}$ was afforded in $92 \%$ yield and $77 \%$ ee (Table 1 , entry 13 ).

Next, the solvent of the asymmetric allylic substitution reaction was further optimized (see ESI $\dagger$ ) and 1,4-dioxane was determined as the optimal one (Table 1, entry 14). To our delight, this optimized condition resulted $4 a$ in high yield (95\%) and with excellent ee (95\%) (Table 1, entry 14). In addition, catalyst (DHQ) ${ }_{2}$ PHAL (1i), the pseudo enantiomer of $\mathbf{1 h}$, was also tested for the reaction, and gave the enantiomer of $\mathbf{4 a}$ in moderate yield and ee value (Table 1 , entry 15 ). $\mathbf{1} \mathbf{j}$ and $\mathbf{1 k}$ are two analogs of catalyst $\mathbf{~ h h}$, but both failed to give better results than 1h (Table 1, entries 16-17). As a summary, the optimal conditions for the asymmetric allylic substitution reaction included using catalyst $\mathbf{1 h}(20 \mathrm{~mol} \%)$ in 1,4-dioxane $(0.05 \mathrm{M})$ at room temperature.

With the optimized conditions in hand, the substrate scope of the asymmetric allylic substitution reaction was investigated. As shown in Table 2, a variety of substituted phenols and $\mathrm{MBH}$ carbonates were well tolerated in this catalytic system, providing the desired products in moderate to high yields (up to 96\%) with excellent enantioselectivities (up to 95\%). The substituents' position in the phenyl ring of phenol 2 had no significant impact on the enantioselectivity $(\mathbf{4 b}-\mathbf{4 d}, \mathbf{4 e - 4 g}, \mathbf{4 h}-$ $\mathbf{4 j}, \mathbf{4 k - 4 m}$ ). Both electron-donating and electron-withdrawing substituents were compatible with this catalytic system (4b4n), although lower yields were observed when the substrates

Table 2 Substrate scope of the asymmetric allylic substitution reaction ${ }^{a, b, c}$

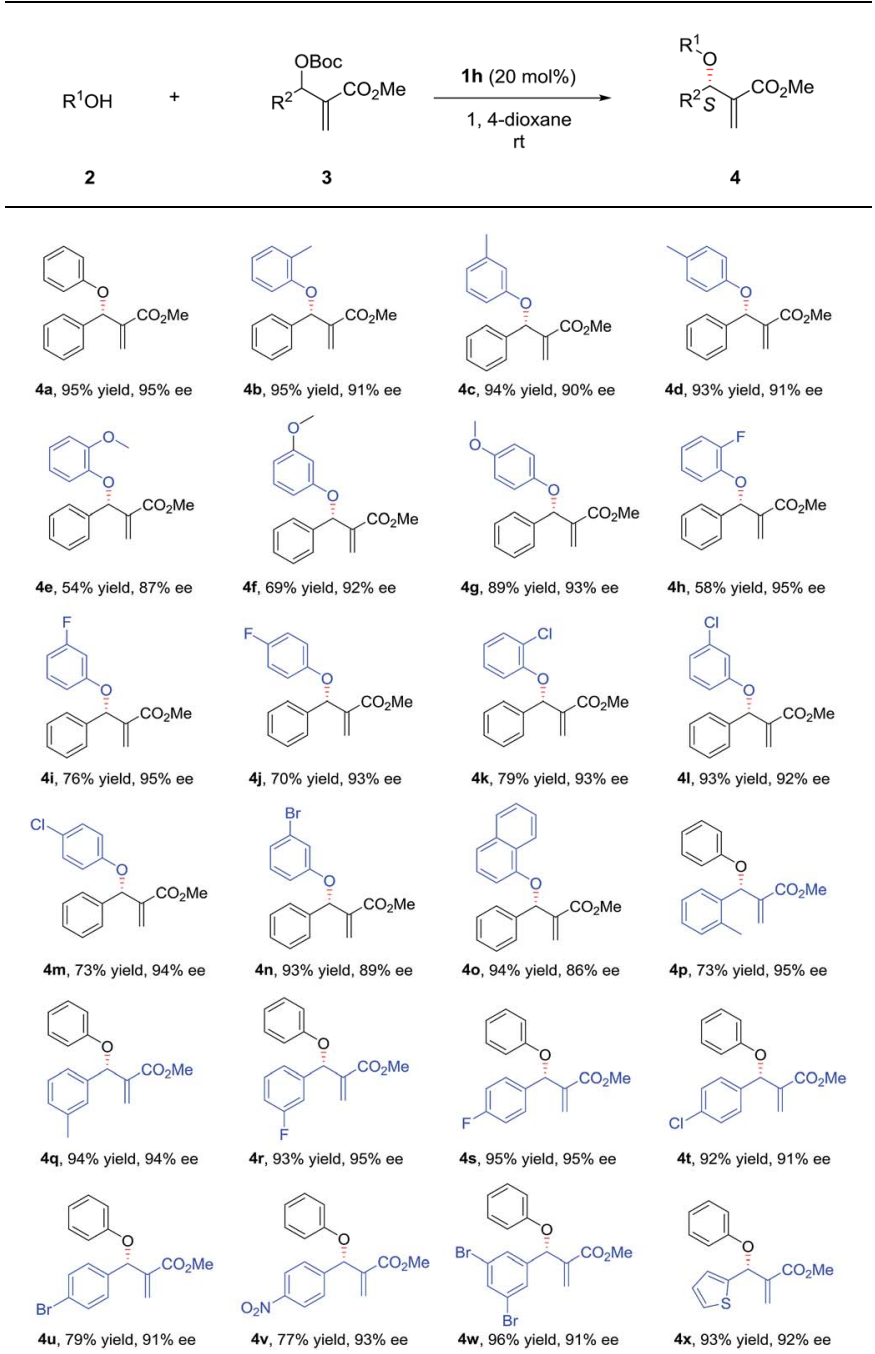

${ }^{a}$ Unless otherwise noted, the reaction was carried out with $2(0.1$ $\mathrm{mmol}), 3(0.3 \mathrm{mmol})$ and $\mathbf{1 h}(20 \mathrm{~mol} \%)$ in $2 \mathrm{~mL} \mathrm{1,4-dioxane} \mathrm{at} \mathrm{room}$ temperature. ${ }^{b}$ The isolated yield. ${ }^{c}$ Determined by HPLC. 
with electron-withdrawing substituents (4h-4n) were used except for $\mathbf{4 l}$ and $\mathbf{4 n}$. The reaction with 1-naphthol gave a slightly decreased ee under the optimal conditions (4o). With respect to $\mathrm{MBH}$ carbonate 3 , we were pleased to observe very satisfactory results for the desired products $(\mathbf{4} \mathbf{p}-\mathbf{4 x})$, although three compounds $(\mathbf{4} \mathbf{p}, \mathbf{4 u}$ and $\mathbf{4 v})$ had moderate yields. Both the substituents' position and electronic nature of the aromatic rings in 3 had little impact on the yields and enantioselectivity. The substrates with disubstituted phenyl ring (4w) and with a heterocyclic ring (4x) were also well tolerated in the optimized conditions. However, when the $\mathrm{MBH}$ carbonate from propionaldehyde was used, the corresponding allylic substitution product could not be detected.

In the process of optimizing the reaction conditions, we synthesized the $\mathrm{MBH}$ carbonate $\mathbf{5 \mathbf { a } ^ { \mathbf { 1 0 } }}$ and found that it could generate $\mathbf{4 a}$ with high yield and ee under the catalysis of $\mathbf{1 h}$ (Scheme 1, eqn (a)). To the best of our knowledge, such a stereoselective transformation has not been reported before in literature. ${ }^{11}$ And it represents an alternative way to the synthesis of chiral multifunctional aryl allyl ethers. To determine the absolute configuration of $\mathbf{4}$, we conducted a reaction of $\mathbf{4} \mathbf{g}$ with CAN (ceric ammonium nitrate) and the valuable chiral $\mathrm{MBH}$ alcohol 6 was isolated with the ee value retained (Scheme 1, eqn (b)). ${ }^{12}$ By comparing the optical rotation value of 6 with those in literature reports, ${ }^{7 a, 7 c, 7 f}$ the stereochemistry of 6 and 4 was determined as $S$ configuration.

To demonstrate the potential application of this methodology, the 1,3-dipolar cycloaddition reaction of the aryl allyl ether 4a with chlorobenzaldoxime was performed, and two diastereomers $7 \mathbf{a}$ and $\mathbf{7} \mathbf{a}^{\prime}$ were isolated with high yield and ee (Scheme 1, eqn (c)). ${ }^{13}$

Based on the experimental observation and literature reports, ${ }^{7 \boldsymbol{f , 1 3 , 1 4}}$ a plausible transition state is proposed for the asymmetric allylic substitution reaction (Scheme 2). First, nucleophilic addition to the vinylic moiety of $\mathrm{MBH}$ carbonate 3a (a)

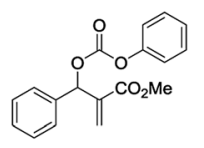

$5 \mathbf{a}$

(b)

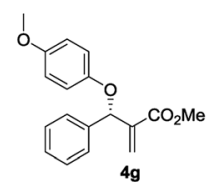

(c)

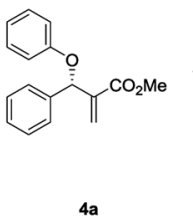

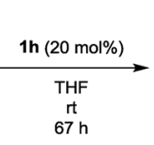

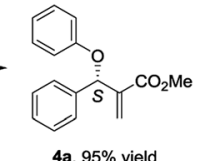

$4 a, 95 \%$ yield
$90 \%$ ee

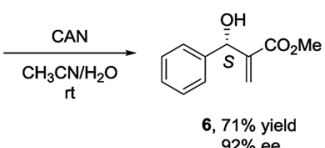

$6,71 \%$ yield
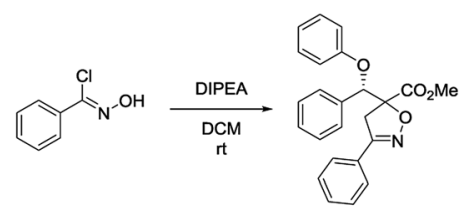

$80 \%$ yield, $d r=1: 1$ $7 a, 40 \%$ yield, $90 \%$ ee
Scheme 1 (a) Synthesis of aryl allyl ether 4a from MBH carbonate 5a by nucleophilic catalysis. (b) Synthesis of chiral MBH alcohol 6. (c) 1,3dipolar cycloaddition reaction of aryl allyl ether $4 a$ and chlorobenzaldoxime.

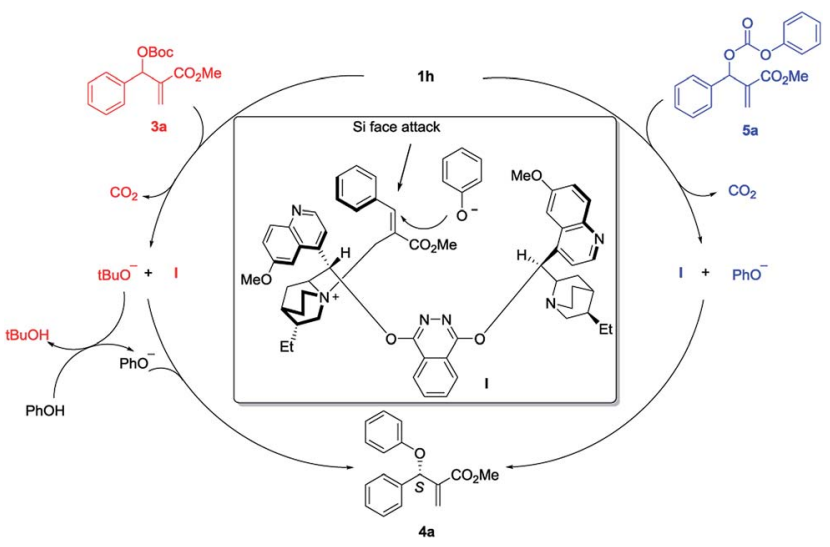

Scheme 2 Proposed mechanism of the asymmetric allylic substitution reaction.

by (DHQD) ${ }_{2}$ PHAL $\mathbf{1 h}$ results in the intermediate $\mathbf{I}$ and $t \mathrm{BuO}^{-}$ with releasing one molecule of $\mathrm{CO}_{2}$. Then the $t \mathrm{BuO}^{-}$deprotonates the pronucleophile $\mathrm{PhOH}$ and affords $\mathrm{PhO}^{-}$. As for the $\mathrm{MBH}$ carbonate $\mathbf{5 a}$, nucleophilic attack by $\mathbf{1 h}$ gives intermediate I and nucleophile $\mathrm{PhO}^{-}$directly with releasing the $\mathrm{CO}_{2}$. The intermediate I would be preferentially formed as the $E$-isomer in accordance with the literature reports. The $\pi-\pi$ stacking between the quinoline moiety and phenyl ring not only stabilizes the cation intermediate $\mathbf{I}$, but also shields the $R e$-face of the alkene for enantioselective control. Finally, the nucleophile $\mathrm{PhO}^{-}$would presumably approach the $\mathrm{Si}$-face in the preferable $\mathrm{S}_{\mathrm{N}} 2^{\prime}$ /anti elimination manner to give the final product $\mathbf{4 a}$.

In conclusion, we have successfully developed an asymmetric allylic $O$-substitution reaction of $\mathrm{MBH}$ carbonates with less-nucleophilic phenols mediated by nucleophilic amine catalyst. A series of chiral multifunctional aryl allyl ethers were obtained in moderate to high yield (up to 96\%) with excellent enantioselectivity (up to 95\%). In addition, the $\mathrm{MBH}$ phenyl carbonate was synthesized and found to be able to generate the same chiral aryl allyl ether with excellent enantioselectivity by nucleophilic catalysis. The synthetic potential of the disclosed methodology was demonstrated by the synthesis of chiral $\mathrm{MBH}$ alcohol and the 1,3-dipolar cycloaddition reaction of the aryl allyl ether with chlorobenzaldoxime.

\section{Conflicts of interest}

There are no conflicts to declare.

\section{Acknowledgements}

We gratefully acknowledge the financial support from the National Science Foundation of China (21602018, 21272029).

\section{Notes and references}

1 For selected reviews, see: (a) W.-Y. Huang, S. Anwar and K. Chen, Chem. Rec., 2017, 17, 1; (b) D. Basavaiah, B. S. Reddy and S. S. Badsara, Chem. Rev., 2010, 110, 5447; 
(c) P. Xie and Y. Huang, Org. Biomol. Chem., 2015, 13, 8578; (d) K. C. Bharadwaj, RSC Adv., 2015, 5, 75923.

2 For selected reviews, see: (a) R. Rios, Catal. Sci. Technol., 2012, 2, 267; (b) Y. C. Fan and O. Kwon, Chem. Commun., 2013, 49, 11588; (c) T.-Y. Liu, M. Xie and Y.-C. Chen, Chem. Soc. Rev., 2012, 41, 4101; (d) Y. Wei and M. Shi, Chem. Rev., 2013, 113, 6659; (e) H. Pellissier, Tetrahedron, 2017, 73, 2831.

3 For selected examples, see: (a) X. Wang, X. Wang, Z. Han, Z. Wang and K. Ding, Angew. Chem., Int. Ed., 2017, 56, 1116; (b) J. Liu, Z. Han, X. Wang, F. Meng, Z. Wang and K. Ding, Angew. Chem., Int. Ed., 2017, 56, 5050; (c) Y. Zhu, Y. Mao, H. Mei, Y. Pan, J. Han, V. A. Soloshonok and T. Hayashi, Chem.-Eur. J., 2018, 24, 8994; (d) X. Wang, P. Guo, Z. Han, X. Wang, Z. Wang and K. Ding, J. Am. Chem. Soc., 2014, 136, 405; (e) S. Gowrisankar, H. S. Lee, S. H. Kim, K. Y. Lee and J. N. Kim, Tetrahedron, 2009, 65, 8769.

4 (a) D. Basavaiah, A. J. Rao and T. Satyanarayana, Chem. Rev., 2003, 103, 811; (b) D. Basavaiah, K. V. Rao and R. J. Reddy, Chem. Soc. Rev., 2007, 36, 1581; (c) V. Singh and S. Batra, Tetrahedron, 2008, 64, 4511.

5 (a) C. G. L. Junior and M. L. A. A. Vasconcellos, Bioorg. Med. Chem., 2012, 20, 3954; (b) C.-R. Yu, L.-H. Xu, S. Tu, Z.-N. Li and B. Li, J. Fluorine Chem., 2006, 127, 1540; (c) M. Cocco, C. Pellegrini, H. Martínez-Banaclocha, M. Giorgis, E. Marini, A. Costale, G. Miglio, M. Fornai, L. Antonioli, G. López-Castejón, A. Tapia-Abellán, D. Angosto, I. HafnerBratkovič, L. Regazzoni, C. Blandizzi, P. Pelegrín and M. Bertinaria, J. Med. Chem., 2017, 60, 3656.

6 (a) B. M. Trost, H.-C. Tsui and F. D. Toste, J. Am. Chem. Soc., 2000, 122, 3534; (b) B. M. Trost, O. R. Thiel and H.-C. Tsui, J. Am. Chem. Soc., 2002, 124, 11616; (c) B. M. Trost, M. R. Machacek and H.-C. Tsui, J. Am. Chem. Soc., 2005, 127, 7014; (d) B. M. Trost and M. K. Brennan, Org. Lett., 2007, 9, 3961; (e) O. Roy, A. Riahi, F. Hénin and J. Muzart, Tetrahedron, 2000, 56, 8133.

7 (a) P. Shanmugam and P. Rajasingh, Chem. Lett., 2002, 1212; (b) B. Zhu, L. Yan, Y. Pan, R. Lee, H. Liu, Z. Han,
K.-W. Huang, C.-H. Tan and Z. Jiang, J. Org. Chem., 2011, 76, 6894; (c) X. Feng, Y.-Q. Yuan, H.-L. Cui, K. Jiang and Y.-C. Chen, Org. Biomol. Chem., 2009, 7, 3660; (d) P. Xie, Y. Huang and R. Chen, Org. Lett., 2010, 12, 3768; (e) D. Basavaiah, N. Kumaragurubaran, D. S. Sharada and R. M. Reddy, Tetrahedron, 2001, 57, 8167; (f) J. N. Kim, H. J. Lee and J. H. Gong, Tetrahedron Lett., 2002, 43, 9141; (g) A. Patra, A. K. Roy, B. S. Joshi, R. Roy, S. Batra and A. P. Bhaduri, Tetrahedron, 2003, 59, 663; (h) Y. Du, X. Han and X. Lu, Tetrahedron Lett., 2004, 45, 4967.

8 (a) L. Jin, S. Zhao and X. Chen, Molecules, 2018, 23, 1421; (b) S. Zhao, Y.-Y. Zhao, J.-B. Lin, T. Xie, Y.-M. Liang and P.-F. Xu, Org. Lett., 2015, 17, 3206; (c) S. Zhao, J.-B. Lin, Y.-M. Liang and P.-F. Xu, Org. Lett., 2014, 16, 1802.

9 (a) K. C. Majumdar and R. K. Nandi, Tetrahedron, 2013, 69, 6921; (b) A. M. M. Castro, Chem. Rev., 2004, 104, 2939; (c) S. Kotha and M. Meshram, Chem.-Asian J., 2018, 13, 1758; (d) N. W. Reich, C.-G. Yang, Z. Shi and C. He, Synlett, 2006, 1278; (e) D. M. X. Donnelly, T. O'Cridain and M. O'Sullivan, J. Chem. Soc., Chem. Commun., 1981, 1254.

10 M. Pittelkow, R. Lewinsky and J. B. Christensen, Synthesis, 2002, 15, 2195.

11 (a) R. Galeazzi, G. Martelli, G. Mobbili, M. Orena and S. Rinaldi, Org. Lett., 2004, 6, 2571; (b) M. Ciclosi, C. Fava, R. Galeazzi, M. Orena and J. Sepulveda-Arques, Tetrahedron Lett., 2002, 43, 2199.

12 T. Fukuyama, A. A. Laird and L. M. Hotchkiss, Tetrahedron Lett., 1985, 26, 6291.

13 (a) H.-L. Liu, M.-S. Xie, G.-R. Qu and H.-M. Guo, J. Org. Chem., 2016, 81, 10035; (b) T. Nishimine, H. Taira, E. Tokunaga, M. Shiro and N. Shibata, Angew. Chem., Int. Ed., 2016, 55, 359; (c) S. Okusu, H. Okazaki, E. Tokunaga, V. A. Soloshonok and N. Shibata, Angew. Chem., Int. Ed., 2016, 55, 6744; (d) T. Furukawa, T. Nishimine, E. Tokunaga, K. Hasegawa, M. Shiro and N. Shibata, Org. Lett., 2011, 13, 3972.

14 M. Baidya, G. Y. Remennikov, P. Mayer and H. Mayr, Chem. Eur. J., 2010, 16, 1365. 